\title{
PENINGKATAN KEAKTIFAN PESERTA DIDIK DALAM PEMBELAJARAN ONLINE MATEMATIKA DENGAN MENGGUNAKAN MEDIA GOOGLE CLASSROOM
}

\author{
Erning Yustiana Dewi" ${ }^{*}$, Alfian Mubarok ${ }^{2}$ \\ ${ }^{1}$ SMPN 2 Jawilan, ${ }^{2}$ SMPN 2 Kopo \\ erningdewi00@gmail.com ${ }^{* 1}$, masfian2911@gmail.com ${ }^{2}$
}

\begin{abstract}
Based on the results of questionnaires and observations of class VIII D students, there was an increase in students' activeness in online learning using Google Classroom media. This Classroom Action Research (CAR) was carried out from Pre-cycle observations to Cycle I and Cycle II, which aims to determine the increasing activity of students in learning activities using Google Classroom media. After carrying out the research, it can be concluded that the average increase in students' activeness in the pre-cycle learning is $41.87 \%$, in Cycle I phase $49.37 \%$, and in Cycle II phase is $65.62 \%$. The research work indicator has been exceeded in the second cycle phase, so this research is stopped only until the second cycle phase. So that it can be concluded from this research that online learning using Google Classroom media can increase students' learning activity. The results of this study are expected to encourage educators to participate in this research and motivate other educators to conduct action research with other online learning media and themes to increase professionalism as an educator.
\end{abstract}

Keywords: student activity, Google Classroom media, online learning

\begin{abstract}
Abstrak
Berdasarkan hasil angket dan pengamatan peserta didik kelas VIII D terdapat peningkatan keaktifan peserta didik dalam pembelajaran online dengan media Google Classroom. Penelitian Tindakan Kelas ( PTK ) ini dilakukan mulai dari observasi Pra siklus ke siklus I dan Siklus II yang bertujuan untuk mengetahui meningkatnya keaktifan peserta didik dalam kegiatan pembelajaran dengan media Google Classroom. Sesudah dilaksanakan penelitian, dapat disimpulkan bahwa rata-rata peningkatan keaktifan peserta didik dalam pembelajaran pada Pra siklus sebesar 41,87\%, pada fase Siklus I sebesar 49,37\% dan pada fase siklus II sebesar 65,62\%. Pada fase siklus II indicator kerja penelitian sudah terlampaui, maka penelitian ini dihentikan hanya sampai pada fase Siklus II. Sehingga bisa diambil kesimpulan dari penelitian ini bahwa pembelajaran daring dengan menggunakan media Google Classrom dapat meningkatkan keaktifan belajar peserta didik. Hasil penelitian ini diharapkan bisa mendorong para pendidik untuk ikut melakukan penelitian ini dan memotivasi pendidik lain untuk melakukan penelitian tindakan dengan tema dan media pembelajaran daring yang lainnya sebagai upaya meningkatkan profesionalisme sebagai seorang pendidik.
\end{abstract}

Kata Kunci : Keaktifan peserta didik, media Google Classroom, pembelajaran online

Received: April 03, 2021 / Accepted: April 27, 2021 / Published Online: April 30, 2021 


\section{PENDAHULUAN}

Termuat di dalam UU No. 20 Tahun 2003 tentang Sisdiknas, bahwa definisi dari pendidikan adalah usaha yang secara sadar dan terencana untuk mewujudkan suasana belajar dan proses belajar agar peserta didik dengan aktif dapat mengembangkan potensi yang ada dalam dirinya untuk memiliki kekuatan dalam aspek spiritual keagamaan, pengendalian diri, kepribadian, akhlak mulia, kecerdasan dan ketrampilan yang dibutuhkan doleh dirinya, masyarakat, bangsa dan negara.

Setelah terjadi pandemic Covid 19, semua aktivitas di seluruh bidang dilakukan dari rumah. Situasi ini berimbas juga pada dunia pendidikan terutama pada semua peserta didik. Mau tidak mau, suka tidak suka semua stakeholder yang terlibat dalam dunia pendidikan mulai dari pendidik, orang tua dan peserta didik harus siap melaksanakan model pembelajaran yang baru yaitu dengan menggunakan perangkat teknologi informasi supaya proses kegiatan belajar mengajar tetap bisa dilaksanakan secara optimal.

Pembelajaran dari rumah atau yang sering disebut BDR memang tidak mudah. Pembelajaran yang awalnya dilaksanakan secara tatap muka langsung dalam kelas, sekarang dilakukan secara online ( daring ) dari jarak jauh. Maka disini perlu menggunakan strategi yang tepat untuk digunakan. Peran Pendidik dan orang tua di rumah sangat diperlukan dalam membimbing anak-anaknya agar tetap melaksanakan aktifitas pembelajaran meskipun dilakukan secara online ( daring ).

Dan hal yang sangat penting sebagai seorang pendidik, harus cerdas dalam memilih media pembelajaran yang tepat dan sesuai dengan materi yang akan di sampaikan pada peserta didik pada kegiatan pembelajaran. Kebanyakan saat ini peserta didik lebih menyukai kemajuan teknologi interaktif atau yang bersifat saling melakukan interaksi, dalam arti media pembelajaran yang digunakan memuat banyak gerakan animasi pada display (tampilan) agar lebih menarik para peserta didik dalam pembelajaran. Oleh karena itu, seorang pendidik harus faham apa yang diinginkan dan disukai peserta didik sesuai dengan zamannya.

Dalam SE Mendikbud No. 4 Tahun 2020, yang menyarankan semua aktivitas di institusi bidang pendidikan harus menjaga jarak dan seluruh penyampaian materi dalam pembelajaran disampaikan dari rumah masing-masing secara daring (online). System pembelajaran daring (online) adalah system pembelajaran tatap muka antara pendidik dan peserta didik, namun dilakukan secara online maupun live dengan jaringan internet. Pendidik harus memastikan kegiatan pembelajaran tetap berjalan kondusif meskipun tidak bertatap muka langsung 
dengan peserta didik. Jadi solusi dalam masalah ini, seorang pendidik dituntut untuk bisa merancang suatu media pembelajaran sebagai inovasi dengan menggunakan media online.

Dengan berbagai macam hambatan yang dialami oleh pendidik dan peserta didik, maka disini pengajar melakukan inovasi pulang dalam melakukan proses belajar mengajar. macam media yang ada untuk bisa membantu dan memudahkan belajar agar bisa meningkatkan prestasi belajar, salah satunya adalah media Google Classroom.

Google Classroom merupakan layanan gratis yang diluncurkan oleh Google untuk dunia pendidikan yang bertujuan untuk memudahkan penyampaian materi dan menilai tugas dengan tanpa kertas. Tujuan utamanya adalah memudahkan untuk berbagi file baik materi maupun soal dari pendidik kepada peserta didik. Dan Google Classroom juga memudahkan peserta didik dan pendidik dalam pengumpulan tugas, dan untuk menumbuhkan cara berkomunikasi yang lebih baik. Aplikasi dari Goole yang sangat popular seperti google document, google spreadsheet, google slide, gmail dan google calender langsung terintegrasi didalam Google Classroom. Pendidika akan mengundang peserta didik ke dalam kelas mereka dengan menggunakan kode dari domain sekolah. Selain itu, melalui aplikasi google semua pendidik dapat melakukan mulai dari proses pembelajaran, pendistribusian tugas serta memeriksa tugas peserta didiknya.

Tujuan dari penelitian ini adalah untuk mengetahui peningkatan keaktifan peserta didik dalam kegiatan belajar secara online dengan media google classroom pada peserta didik kelas 8D di SMP Negeri 2 Jawilan pada semester gasal Tahun Pelajaran 2020-2021

\section{METODE PENELITIAN}

Penelitian ini merupakan Penelitian Tindakan Kelas (PTK), yang menjadi obyek dalam penelitian ini adalah peserta didik kelas 8D di SMP Negeri 2 Jawilan yang berjumlah 32 pada semester gasal Tahun Pelajaran 2020-2021. Penelitian ini di rancang dan dilaksanakan melalui 4 tahapan, yaitu : Pertama, Perencanaan (Planning) yang terdiri dari pengamatan terhadap output belajar peserta didik pada pertemuan sebelumnya, mengidentifikasi factorfaktor yang berpengaruh terhadap aktifitas belajar peserta didik, merencanakan tindakan apa yang akan dilakukan dan mempersiapkan semua perangkat pembelajaran yang akan digunakan. Kedua, pelaksanaan tindakan yaitu aktivitas pembelajaran di ruang kelas google classroom sesuai dengan yang telah di rencanakan dan tertuang dalam RPP. Ketiga adalah pengamatan yang dilakukan saat aktivitas yang kedua dilakukan, kedua tahap ini tidak dapat dipisahkan karena sangat berpengaruh pada output hasil akhir penelitian. Keempat adalah refleksi yaitu kegiatan menyampaikan kembali apa yang telah dilakukan dalam tindakan. 
Jurnal Lebesgue : Jurnal Ilmiah Pendidikan Matematika, Matematika dan Statistika

Erning Yustiana Dewi, Alfian Mubarok

Volume 2, No. 1, April 2021 hal.136-144

DOI Artikel : 10.46306/lb.v2i1.59

Kegiatan yang dilakukan adalah mengidentifikasi kelemahan dan kekurangan aktivitas Siklus I untuk menyusun rencana/planning perbaikan pada siklus II, demikian menurut pendapat Suharsimi Arikunt dalam Jalil (2014:11) yang digambarkan seperti pada bagan berikut :

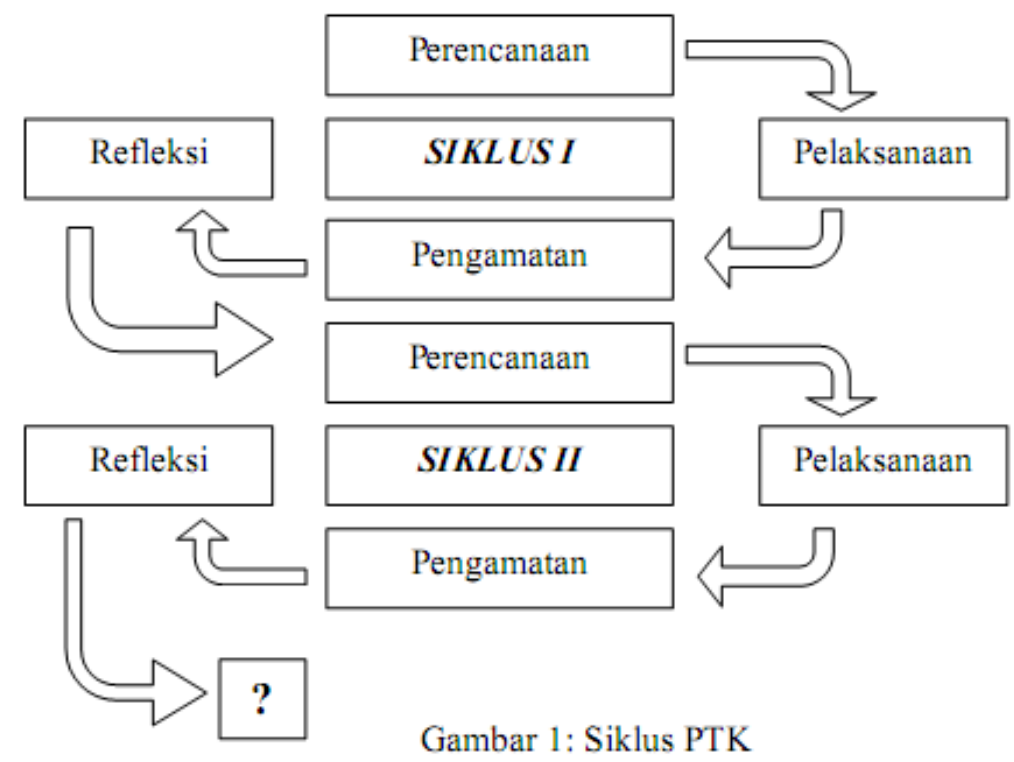

Data penelitian diperoleh dengan jalan observasi dan data dokumentasi. Lembar observasi digunakan untuk menggali data mengenai aplikasi model pembelajaran dan tingkat keaktifan pesrta didik mulai dari tahap pra siklus sampai pada aktifitas siklus I dan siklus II. Lembar observasi ini diisi oleh pendidik sebagai peneliti dan juga oleh teman sejawatnya. Metode kedua adalah studi dokumentasi yang digunakan peneliti untuk menggali data-data pendukung untuk melengkapi data keaktifan peserta didik yaitu dengan buku absen peserta didik dan bukti catatan pengumpulan tugas.

Indikator kinerja yang ingin didapatkan pada Penelitian Tindakan Kelas (PTK) ini yaitu meningkatnya keaktifan belajar Matematika pada peserta didik kelas 8D SMPN 2 Jawilan Serang. Sebagai patokan keberhasilan pelaksanaan penelitian ini yaitu apabila keaktifan belajar peserta didik melebihi $65 \%$ yaitu keaktifan belajar peserta didik mulai dari pra siklus sampai siklus I dan siklus II yang dapat dilihat pada tabel dibawah ini.

\begin{tabular}{|c|c|}
\hline Kriteria Penilaian & Kualifikasi \\
\hline$>65 \%$ & Berhasil \\
\hline$<65 \%$ & Tidak Berhasil \\
\hline
\end{tabular}

Tabel 1. Indikator Kinerja 
Jurnal Lebesgue : Jurnal Ilmiah Pendidikan Matematika, Matematika dan Statistika

Erning Yustiana Dewi, Alfian Mubarok

Volume 2, No. 1, April 2021 hal.136-144

DOI Artikel : 10.46306/lb.v2i1.59

\section{HASIL DAN PEMBAHASAN}

Pelaksanaan pembelajaran pra siklus memakai WhatsApp Web dengan pembelajaran yg berpusat pada Pendidik, dimana Pendidik menjadi sumber informasi, pendidik menggunakan metode tanya jawab pada proses pembelajaran. Observer mengamati keaktifan peserta didik dengan melihat keaktifan dalam tanya jawab dibantu dengan menggunakan lembar observasi yang berisi lima indicator keaktifan peserta didik. Hasil dari observasi menunjukkan bahwa indicator pertama yaitu perhatian sebesar $84,37 \%$, indicator kedua tentang kerjasama dan interaksi social sebesar $28,12 \%$, indicator ketiga tentang mengemukakan pendapat atau ide sebesar $6,25 \%$, indicator keempat pemecahan masalah sebesar $12,5 \%$ dan indicator terakhir yaitu disiplin sebesar $78,12 \%$

Dari hasil instrument keaktifan tersebut, bisa disimpulkan bahwa keaktifan peserta didik yg dilihat dari indikator perhatian dan disiplin telah melebihi 65\% namun berdasarkan instrumen kerjasama \& hubungan sosial, pendapat dan ide, pemecahan masalah belum melebihi $65 \%$ sehingga bisa disimpulkan bahwa keaktifan peserta didik belum seluruhnya aktif.

Pelaksanaan Siklus I pada penelitian ini dengan menerapkan pembelajaran daring dengan media Google Classroom, pelaksanaan tindakan dilakukan untuk mengatasi permasalahan keaktifan peserta didik yang masih rendah dengan melakukan kegiatan belajar mengajar oleh pendidik sebagai pelaku tindakan dan pengamatan tindakan oleh pengamat terhadap semua aktifitas pada saat pelaksanaan tindakan. Siklus I ini dilakukan dengan 4 tahapan, yaitu perencanaan/planning, aplikasi/tindakan, pengamatan/observasi dan refleksi.

Pengamatan dilakukan dengan cara mengamati keaktifan peserta didik dengan menggunakan catatan di lembar observasi. Data hasil observasi pada Siklus ke-1 ini menerangkan bahwa indicator ke-1 tentang perhatian sebesar $84,3 \%$, indicator ke-2 tentang kerjasama dan hubungan social sebesar $34,37 \%$, indicator yang ke-3 tentang mengemukakan pendapat / ide sebesar 25\%, indicator ke-4 tentang pemecahan masalah sebesar 21,87\% dan untuk indicator disiplin sebesar 81,25\% seperti yang terlihat pada Tabel. 2 dibawah ini :

\begin{tabular}{|c|l|c|c|}
\hline No & \multicolumn{1}{|c|}{ Indikator } & Pra siklus & Siklus I \\
\hline 1 & Perhatian & $84,37 \%$ & $84,37 \%$ \\
\hline 2 & $\begin{array}{l}\text { Kerjasama dan Hubungan } \\
\text { Sosial }\end{array}$ & $28,12 \%$ & $34,37 \%$ \\
\hline 3 & Mengemukakan Pendapat atau & $6,25 \%$ & $25 \%$ \\
\hline
\end{tabular}




\begin{tabular}{|c|l|c|c|}
\hline & Ide & & \\
\hline 4 & Pemecahan Masalah & $12,5 \%$ & $21,87 \%$ \\
\hline 5 & Disiplin & $78,12 \%$ & $81,25 \%$ \\
\hline \multirow{2}{*}{} & Rata-rata & $41,87 \%$ & $49,37 \%$ \\
\hline
\end{tabular}

Tabel .2. Persentase keaktifan Belajar Pra Siklus dan Siklus I

Berdasarkan data hasil studi dokumentasi pengumpulan tugas sebagai data ke-3 yaitu mengenai keaktifan peserta didik, menunjukkan bahwa 26 dari 32 peserta didik atau sebesar $81,25 \%$ peserta didik mengumpulkan tugas tepat waktu yang telah ditentukan oleh pendidik. Siklus II ini terdiri atas 3 tahapan yaitu planning (perencanaan), aplikasi(tindakan) \& pengamatan, dan refleksi.

Dari data hasil pada siklus I, maka disusunlah rencana tindakan untuk Siklus II. Teman sejawat peneliti melakukan observasi dan mengisi lembar observasi yang digunakan sebagai acuan untuk menggali dan mengumpulkan data selama proses pembelajaran berlangsung.

Refleksi yaitu usaha untuk menyelidiki apa yang telah terjadi maupun tidak terjadi pada saat aplikasi tindakan, mulai dari Siklus I sampai siklus terakhir. Hasil dari refleksi tersebut digunakan sebagai acuan untuk memutuskan tindak lanjut penelitian termasuk perubahab tindakan yang mungkin di ambil jika siklus sebelumnya belum mencapai target yang di harapkan.

Data yang didapat dari tindakan observasi pada siklus II dapat dilihat dari Tabel. 3 berikut ini :

\begin{tabular}{|c|l|c|c|c|}
\hline No & \multicolumn{1}{|c|}{ Indikator } & Pra siklus & Siklus I & Siklus II \\
\hline $\mathbf{1}$ & Perhatian & $84,37 \%$ & $84,37 \%$ & $84,37 \%$ \\
\hline $\mathbf{2}$ & $\begin{array}{l}\text { Kerjasama dan Hubungan } \\
\text { Sosial }\end{array}$ & $28,12 \%$ & $34,37 \%$ & $56,25 \%$ \\
\hline $\mathbf{3}$ & $\begin{array}{l}\text { Mengemukakan Pendapat atau } \\
\text { Ide }\end{array}$ & $6,25 \%$ & $25 \%$ & $53,12 \%$ \\
\hline $\mathbf{4}$ & Pemecahan Masalah & $12,5 \%$ & $21,87 \%$ & $50,00 \%$ \\
\hline $\mathbf{5}$ & Disiplin & $78,12 \%$ & $81,25 \%$ & $84,37 \%$ \\
\hline & Rata-rata & $41,87 \%$ & $49,37 \%$ & $65,62 \%$ \\
\hline
\end{tabular}

Tabel 3. Persentase keaktifan Belajar pada Pra Siklus, Siklus I \& Siklus II

Data berdasarkan lembar observasi menampakan bahwa kelima indikator sudah mencapai skor > 50\% dari skor maksimal. Data pada siklus kedua menunjukkan bahwa 
peserta didik teridentifikasi mulai semakin tinggi keaktifannya. Jika ditinjau berdasarkan 5 indikator keaktifan peserta didik tadi, seluruhnya dapat berkontribusi penuh dalam keaktifnya di pembelajaran. Berdasarkan Tabel 3, dapat digambarkan pada histogram sebagai berikut :

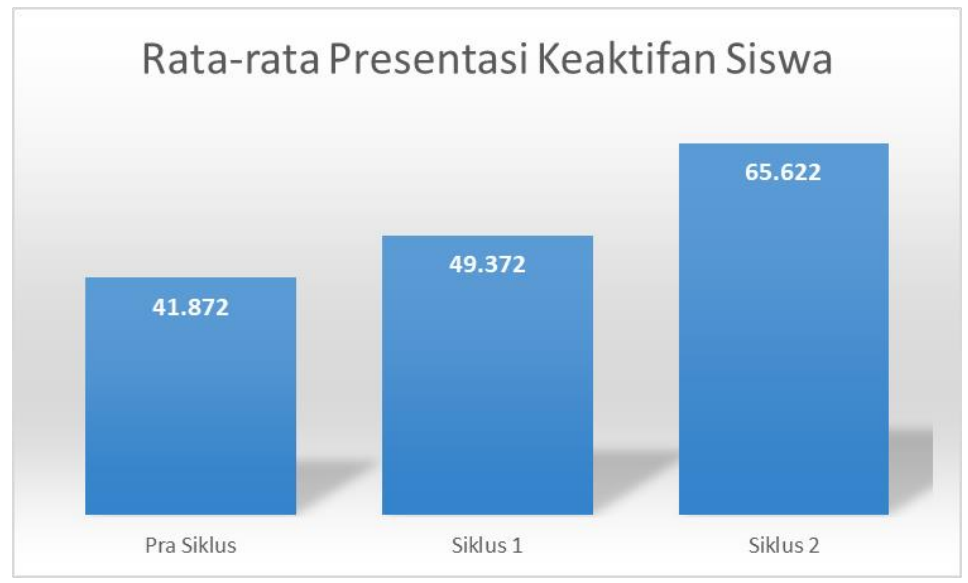

Gambar 2. Diagram rata-rata persentase keaktifan peserta didik Pra Siklus, Siklus I dan Siklus II

Dari hasil penelitian diperoleh bahwa pembelajaran daring dengan memakai google classroom dapat menaikkan aktifitas belajar peserta didik yg selanjutnya diharapkan pula dapat mempertinggi prestasi belajar mereka. Dalam pembelajaran ini, peneliti membuat materi ajar yang jelas \& bisa dipahami dengan mudah oleh peserta didik sehingga peserta didik lebih mudah untuk belajar. Kemudian mengupload materi tadi pada aplikasi google classroom. Hasil yang diperoleh ini sesuai dengan hasil yg serupa yg telah dilakukan oleh peneliti lain yang berjudul "Pengaruh E-Learning dengan Google Classroom terhadap Hasil dan Motivasi Belajar Biologi pada siswa kelas 11 MIA SMA Nurul Falah Pekanbaru". ( Rikizaputra \& Hanna Sulastri,2020).

Pemanfaatan Google Classroom bisa digunakan melalui banyak perangkat, bisa melalui computer dan juga bisa melalu perangkat HP Android. Google Classroom adalah sebuah platform yang digunakan untuk membuat kelas di dunia maya. Goole classroom bisa juga digunakan untuk mendistribusikan tugas, pengumpulan tugas sampai menilai tugas yang diserahkan oleh peserta didik.

Menurut Hakim, Google Classroom dibuat untuk memudahkan timbal balik antara guru dan siswanya di dunia maya. Google classroom juga memberikan peluang kepada peserta didik agar bisa mengemukakan gagasan keilmuan yang dimiliki pendidik untuk peserta didiknya 
Jurnal Lebesgue : Jurnal Ilmiah Pendidikan Matematika, Matematika dan Statistika

Erning Yustiana Dewi, Alfian Mubarok

Volume 2, No. 1, April 2021 hal.136-144

DOI Artikel : 10.46306/lb.v2i1.59

Waktu untuk memberikan materi dan untuk memberi tugas mandiri kepada peserta didik sangat leluasa. Pendidik juga bisa memberikan kesempatan bagi semua peserta didiknya secara online untuk berdiskusi di ruang diskusi. Jadi, asumsi dalam penelitian ini, bahwa dengan menggunakan media Goole Classroom tujuan pembelajaran akan lebih mudah di realisasikan dan belajar menjadi lebih mudah dan bermakna. Sehingga Google Classroom ini sebenarnya memberikan kemudahan pada pendidik dalam mengelola pembelajaran dan memberikan materi secara tepat dan akurat kepada peserta didik. (Hakim, $2016: 58$ )

\section{KESIMPULAN DAN SARAN}

Simpulan yang dapat diambil dari Penelitian Tindakan Kelas (PTK) ini adalah meningkatnya keaktifan peserta didik dalam pembelajaran moda daring melalui media google clasroom pada masa pandemi Covid-19 mata pelajaran matematika kelas 8D di SMPN 2 Jawilan Serang semester gasal Tahun Pelajaran 2020/2021. Setelah pelaksanaan pembelajaran moda daring dengan menggunakan media google classroom yang sebelumnya pada tahap Pra Siklus keaktifan peserta didiknya adalah 41,87\% dari 32 siswa, setelah tindakan pada Siklus I, diperoleh data keaktifan rata-rata peserta didik sebesar 49,37\%, dan setelah pelaksanaan siklus II, hasil rata-rata keaktifan siswa menjadi 65,62\%. Berdasarkan dari data yang diperoleh dari tiap siklus, maka ditarik kesimpulan bahwa media google classroom dalam pembelajaran online dapat meningkatkan keaktifan peserta didik di masa pandemic Covid-19 untuk mata pelajaran Matematika kelas VIII D sebesar 16,25\%. Peserta didik di sarankan agar lebih bersemangat dan lebih serius dalam mengikuti pembelajaran sistem daring supaya situasi pembelajaran pada masa pandemi ini tidak mengganggu \& menghambat dalam meraih tujuan belajar, baik secara akademis maupun psikologis \& bagi Pendidik disarankan agar selalu memberikan bimbingan pada semua peserta didik.

\section{DAFTAR PUSTAKA}

Fanny Ahmad Fauzi, \& Puji Lestari. (2020). Implementasi Pembelajaran Individual Head Number Berbasis Google Meet dan Classroom pada Materi Trigonometri. Buana Matematika : Jurnal Ilmiah Matematika Dan Pendidikan Matematika, 10(2), 175-188. doi:10.36456/buanamatematika.v10i2.2568

Friantini, R. N., \& Winata, R. (2020). Disposisi Matematis Dan Kemandirian Belajar Mahasiswa Pada Perkuliahan Daring Berbantuan Google Classroom Masa Covid-19. Jurnal Derivat: Jurnal Matematika Dan Pendidikan Matematika, 7(2), 53-64. doi:10.31316/j.derivat.v7i2.1068 
Jurnal Lebesgue : Jurnal Ilmiah Pendidikan Matematika, Matematika dan Statistika

Erning Yustiana Dewi, Alfian Mubarok

Volume 2, No. 1, April 2021 hal.136-144

DOI Artikel : 10.46306/lb.v2i1.59

Hakim, A,B.(2016). Efektifitas Penggunaan E-Learning Moodle, Google Classroom dan Edmodo.STIMIK ESQ: 2(1-4)

Kurniawati, M., Santanapurba, H., \& Kusumawati, E. (2019). PENERAPAN BLENDED LEARNING MENGGUNAKAN MODEL FLIPPED CLASSROOM BERBANTUAN GOOGLE CLASSROOM DALAM PEMBELAJARAN MATEMATIKA SMP. EDUMAT: Jurnal Pendidikan Matematika, 7(1). doi:10.20527/edumat.v7i1.6827

Jalil, Jasman.2014. Panduan Mudah Penelitian Tindakan Kelas, Jakarta : Prestasi Pustaka Publisher

Mustika, H., \& Nadela, J. (2021). Analisis kualitas pembelajaran matematika pada penggunaan platform google classroom materi kombinatorika. Journal of Didactic Mathematics, 2(1), 1-8. doi:10.34007/jdm.v2i1.579

Pianda, D. (2020). PENINGKATAN KREATIVITAS SISWA DALAM PEMBELAJARAN MATEMATIKA DENGAN GOOGLE CLASSROOM SEBAGAI KELAS DIGITAL BERBANTUAN APLIKASI GEOGEBRA. Al Khawarizmi: Jurnal Pendidikan Dan Pembelajaran Matematika, 4(2), 93. doi:10.22373/jppm.v4i2.7672

Proborini, E., \& Herawati, R. (2021). Penggunaan Google Classroom Sebagai Media Pembelajaran Matematika. WACANA AKADEMIKA: Majalah Ilmiah Kependidikan, 5(1), 17. doi:10.30738/wa.v5i1.8927

Rikizaputra, R., \& Sulastri, H. (2020). Pengaruh E-Learning dengan Google Classroom terhadap Hasil dan Motivasi Belajar Biologi Siswa. Lectura : Jurnal Pendidikan, 11(1), 106-118. https://doi.org/10.31849/lectura.v11i1.3760

Sudijono,Anas.2005. Pengantar Evaluasi Pendidikan. Jakarta : Raja Grafindo Persada

Sulistyowaty, R. K., \& Firdaus, F. (2020). PENERAPAN GOOGLE CLASSROOM DALAM PEMBELAJARAN MATEMATIKA JARAK JAUH UNTUK MENINGKATKAN KEAKTIFAN BELAJAR SISWA. Lentera Sriwijaya: Jurnal Ilmiah Pendidikan Matematika, 2(2), 14-24. doi:10.36706/jls.v2i2.12734

Undang-Undang No. 20 Tahun 2003 tentang Sisdiknas

SE Mendikbud No.4 Tahun 2020 